\title{
Evaluación del extracto etanólico de propóleos en el desarrollo y la inmunidad de pollos de engorde
}

\author{
Fernando Sanabria-Naranjo*, MVZ, Esp.; Luz Marina Parra-González, Bióloga, Esp., MSC ${ }_{1}$
}

${ }_{1}$ Grupo de investigación en Desarrollo Sostenible de los Sistemas Agropecuarios y Agroindustriales (USTAGRI), Facultad de Administración de Empresas Agropecuarias, Universidad Santo Tomás, Bucaramanga, Santander

Recibido: 10 de noviembre del 2014. Aprobado: 15 de diciembre del 2014.

*Autor de correspondencia: Fernando Sanabria Naranjo, Área de Investigación, Universidad Santo Tomás. Carrera 18 \# 9-27, Bucaramanga, Colombia, teléfono: (57) 7 6800801. Correo electrónico: fernandosanabrianaranjo@mail.ustabuca.edu.co

Cómo citar este artículo: Sanabria-Naranjo F, Parra-González LM. Evaluación del extracto etanólico de propóleos en el desarrollo y la inmunidad de pollos de engorde. Spei Domus. 2014;10(21):9-27. doi: http://dx. doi.org/10.16925/sp.v10i21.915

Resumen. Introducción: la industria avícola, con su producción de carne, aporta la proteína animal más económica y con alto valor nutricional para la alimentación humana, pero la presencia de residuos de antibióticos químicos en ella ha generado rechazo; actualmente se busca la inocuidad del alimento, utilizando antibióticos naturales que protejan a las aves, al medio ambiente y a los consumidores. Entre ellos encontramos los propóleos, material que se obtiene de las abejas y posee un alto contenido de flavonoides, además, promueven el desarrollo de las aves de engorde. El objetivo fue evaluar si la adición de propóleos en el agua favorece la productividad del pollo de engorde y mejora el desarrollo inmunológico. Materiales y métodos: se parte de una caracterización química por cromatografía líquida de alta eficiencia con detector de arreglo de diodos (HPLC/DAD); a las aves se les suministra el propóleo seleccionado y se valora su incidencia en los parámetros zootécnicos; se evalúa su efecto antimicrobiano frente a una cepa de referencia de Echerichia coli y la respuesta inmune ante las vacunas aplicadas a las aves. Resultados: se obtuvieron mejoras en la ganancia de peso y la conversión alimenticia, un aumento en la sensibilidad de los antibióticos ante la cepa de E. coli de referencia, se presentaron títulos más altos ante las enfermedades de Gumboro y Newcastle aunque sucedió lo contrario con Bronquitis infecciosa. Conclusiones: es una alternativa económica y técnica para disminuir el uso de antibióticos químicos en la industria avícola ante retos de enfermedades.

Palabras clave: antibiótico, inmunidad, químicos.

\section{Evaluating Ethanolic Extract of Propolis in Broiler Chicken Development and Immunity}

\begin{abstract}
Introduction: The poultry industry provides the cheapest animal protein for human consumption, producing meat with high nutritional value, but the presence of chemical antibiotic residues in this meat has caused it to be rejected. Currently, efforts are being made to guarantee food safety by using natural antibiotics that protect the chickens, the environment, and consumers. One such antibiotic is propolis, a material obtained from bees that has high flavonoid content, and also promotes broiler development. The aim of this study was to evaluate whether the addition of propolis to the broilers' water increased their productivity and improved their immunological development. Materials and methods: The starting point for this study was a chemical characterization by high performance liquid chromatography with photodiode array detection (HPLC/DAD). The selected propolis was administered to the broilers and its impact on zootechnical parameters was measured. Its antimicrobial effect against reference strain Echerichia coli and the immune response against the vaccines given to the broilers was also evaluated. Results: There were improvements in weight gain and feed conversion, and the sensitivity of antibiotics to the E. coli reference strain increased. There were higher titers for Gumboro and Newcastle diseases, but the opposite effect occurred with infectious bronchitis. Conclusions: Propolis is a cost-effective and technological alternative for reducing the use of chemical antibiotics in combating diseases in the poultry industry.
\end{abstract}

Keywords: antibiotic, immunity, chemicals.

\section{Avaliação do extrato etanoico de própolis no desenvolvimento e na imunidade de frangos de corte}

Resumo. Introdução: a indústria avícola com sua produção de carne contribui com a proteína animal mais econômica e com alto valor nutricional para a alimentação humana, mas a presença de resíduos de antibióticos químicos nela gerou rejeição, atualmente se está procurando a segurança alimentar, utilizando antibióticos naturais que protejam as aves, o meio ambiente e os consumidores. Entre eles encontramos a própolis, material que se obtém das abelhas e possui um alto conteúdo de flavonoides, além disso, promove o desenvolvimento das aves de corte. O objetivo foi avaliar se a adição de própolis na água favorece a produtividade do frango de corte e melhora o desenvolvimento imunológico. Materiais e métodos: parte de uma caracterização química por cromatografia líquida de alta eficiência com detector de arranjos de diodos (HPLC/DAD); a própolis selecionada é fornecida às aves e se valoriza sua incidência nos parâmetros zootécnicos; avalia-se seu efeito antimicrobiano contra uma cepa de referência de Escherichia coli e a reposta imune ante as vacinas aplicadas nas aves. Resultados: obtiveram-se melhoras no ganho de peso e na conversão alimentícia, um aumento na sensibilidade dos antibióticos ante a cepa de E. coli de referência, apresentaram-se títulos mais altos ante as doenças de Gumboro e Newcastle embora tenha acontecido o contrário com a Bronquite infecciosa. Conclusões: é uma alternativa econômica e técnica para reduzir o uso de antibióticos químicos na indústria avícola perante desafios de doenças.

Palavras-chave: antibiótico, imunidade, químicos. 


\section{Introducción}

El departamento de Santander es una región destacada en la producción avícola colombiana, especialmente en lo que se refiere a pollo de engorde, ya que promueve más del $25 \%$ del total de la producción nacional, y participa dentro del patrimonio interno bruto departamental con un $3 \%$, con un consumo per cápita anual de 27,1 kilos, alcanzando en el 2013 un incremento de 3,2 kilos por persona/año a nivel nacional. En total en el país se produjeron 1,2 millones de toneladas de carne de pollo, de las cuales el $25 \%$, es decir, aproximadamente 330 mil toneladas salieron de las granjas de Santander [1].

En la producción industrial de la carne de pollo, muchas veces las aves sufren problemas respiratorios durante su ciclo, por lo que es necesario realizar tratamientos a base de antibióticos químicos, pero el corto tiempo de vida del animal no permite esperar en forma prudencial que se eliminen los residuos, quedando trazas de las bases químicas, que al ser consumidas por el hombre, trae como consecuencia una resistencia bacteriana [2].

El uso de antibióticos en sanidad animal es una práctica reconocida a nivel mundial y se constituye como herramienta médica y normativa para evitar el desarrollo de enfermedades [3]. También se han utilizado los antibióticos como promotores de crecimiento (APC) a dosis bajas, en forma preventiva con el fin de disminuir algunas enfermedades en las aves [4].

En los últimos años, los antibióticos promotores de crecimiento (APC) usados en las raciones de animales han sido criticados y presionados legalmente. La razón es que, al parecer, estos fármacos son los causantes del incremento de la resistencia a los antimicrobianos en la medicina humana; además, los alimentos de origen animal tratados con este tipo de medicamento contienen trazas que están siendo incorporadas al organismo humano fomentando la aparición de microorganismos resistentes [5]. De otra parte, el uso continuo de estos APC promueven la aparición de cepas de microorganismos resistentes que al ser consumidos por los humanos los afectan en su salud [6]. Algunas enfermedades diarreicas causan la muerte a más de tres millones de personas al año, cuya etiología son cepas bacterianas de Shigella disentería, Campylobacter, Vibrio cholerae, Escherichia coli y Salmonella, resistentes a ciertos antibióticos y se sospecha que estas enfermedades están presentes en animales de consumo [7].
Una vez implantada la decisión de la prohibición de los APC en Europa [8], se ha intentado buscar alternativas de materias primas de origen natural, como el timol, el carvacrol, las cumarinas, los aceites esenciales y los flavonoides, entre otros, para reemplazar los agentes antimicrobianos químicos [9]. Una fuente rica en flavonoides son los propóleos: resinas producidas por las abejas y utilizadas para prevenir y controlar la proliferación de microorganismos como hongos, virus y bacterias en sus colmenas [10-12]. Si son usados en la alimentación animal, los propóleos inducen incremento en el peso y mayor desarrollo muscular [13].

De acuerdo con la literatura científica, se ha demostrado que los propóleos poseen propiedades inmuno estimulantes al inhibir la enzima ciclo-oxigenasa, la cual actúa sobre las prostaglandinas que tienen la propiedad de inhibir los linfocitos T [14-16].

Los flavonoides presentes en los propóleos son los encargados de ejercer una acción antibacterial, actúan como alteradores del potencial de membrana de las bacterias, al provocar una disipación y pérdida de la capacidad de sintetizar ATP, impedir su movilidad y disminuir su acción patógena [17-19].

El agua, etanol, metanol, propanol, acetato de etilo, ácido acético son solventes polares especiales para solubilizar los componentes de propóleos; sin embargo, el alcohol etílico es reconocido como el mejor solvente para retirar sus principios activos [20,21]. Los extractos del etanol tienen actividad antibacteriana más alta comparada con los extractos acuosos, y la actividad antibacteriana depende de su origen y de la especie bacteriana evaluada [22]. En aves de engorde, durante la primera semana de vida, se ha demostrado un efecto inmunomodulador positivo del extracto etanólico de propóleos sobre la bolsa de Fabricio [23].

El presente estudio tuvo como propósito evaluar el efecto del extracto etanólico de propóleos (EEP) en el desarrollo y la inmunidad de pollos de engorde, como un potencial alternativo para la sustitución de antibióticos químicos en los tratamientos de aves de engorde.

\section{Materiales y métodos}

\section{Toma de muestra}

Se seleccionaron cuatro zonas en Santander y una en Huila para tomar las muestras de propóleos, teniendo en cuenta la producción de estos; luego se procedió a realizar la respectiva dilución, 200 gramos de cada 
una de las muestras en un litro de etanol (alcohol etílico al 96\%), colocándola en un frasco ámbar para evitar el daño lumínico; se envió al laboratorio para realizar la determinación de flavonoides, mediante la prueba de cromatografía líquida de alta eficiencia con detector de arreglo de diodos (HPLC/DAD), demarcándose así:

Muestra 01: propóleos de Apis mellifera proveniente de la vereda El Cebadero, municipio de Lebrija, Santander. Muestra 02: propóleos de Apis mellifera, vereda Guarigua Alta del municipio de San Gil. Muestra 03: propóleos de Tetrágona peranguluta, vereda Limoncitos, municipio de Floridablanca, Santander. Muestra 04: propóleos de Apis mellifera de Garzón, Huila.

\section{Localización}

El experimento se realizó en la Granja Experimental El Limonal, en el municipio de Piedecuesta, de propiedad de la Universidad Santo Tomás, localizada a $17 \mathrm{~km}$ de Bucaramanga, con clima promedio de $24^{\circ} \mathrm{C}$ y una altitud de 1005 msnm, y correspondió a una investigación de tipo exploratorio.

\section{Experimentos o tratamientos}

Se hicieron dos experimentos: en el primero se evaluaron los parámetros zootécnicos de las aves y en el segundo, además de los parámetros zootécnicos, se expusieron los animales ante una cepa de referencia E. coli para evaluar la resistencia ante antibióticos mediante la prueba de Mueller Hinton, y se midieron los anticuerpos por medio de la prueba ELISA en la sangre de las aves para los antígenos aplicados Newcastle, Gumboro y Bronquitis infecciosa.

En el experimento uno, se utilizaron 256 aves de la línea genética Ross (128 hembras y 128 machos), divididos en ocho corrales de 32 aves cada uno, de los cuales 128 consumieron extracto etanólico de propóleos (EEP) en el agua de bebida, a razón de $0,4 \mathrm{ml}$ por animal, repartidos durante los cuarenta días del experimento, dosificados así: los tres primeros días de la primera, segunda y tercera semana, dos días de la cuarta y cuatro días de la quinta, y 128 aves sirvieron de testigo. Ambos lotes recibieron la misma cantidad de alimento e iguales condiciones de manejo, de acuerdo con la sugerencia de Aviagen, casa matriz de la línea genética. Semanalmente se realizaron pesajes de las aves y la mortalidad se diagnosticó de acuerdo con su incidencia. A los catorce días de vida, se aplicaron antígenos comerciales contra la enfermedad de Newcastle, Bronquitis y Gumboro en el ojo y el pico.

En el experimento dos, se seleccionaron al azar 60 aves del experimento uno, cuando tenían 27 días; 30 aves que se encontraban consumiendo EEP y 30 del lote testigo fueron alojadas en ocho jaulas a una distancia de $1 \mathrm{~m}$, para someterse a una inoculación de una cepa de referencia de E. coli y conformar cuatro tratamientos así:

- T1: 15 animales sin consumo de EEP con infección de E. coli

- T2: 15 animales sin consumo de EEP sin infección de E. coli

- T3: 15 animales con consumo de EEP con infección de E. coli

- T4: 15 animales con consumo de EEP sin infección de E. coli

Del total de las aves infectadas, cinco fueron inoculadas directamente en el esófago con un hisopo y a las otras se les suministró la cepa por el agua de bebida.

Al concluir el experimento, se tomaron muestras de sangre de la vena alar para evaluar por medio de la prueba ELISA la cantidad de anticuerpos resultantes de los dos lotes de aves, igualmente se procedió al sacrifico de las aves para la toma de muestras de órganos internos, se analizaron por medio de cultivos bacteriológicos y se evaluaron los resultados de resistencia bacteriana, mediante el método de difusión en disco.

\section{Análisis estadístico}

Para el primer experimento, se utilizó estadística descriptiva, por medio de tablas de promedios, desviación estándar y número de aves en una base semanal, y gráficos de cajas para el peso, el consumo y la conversión.

El segundo experimento consistió en la asignación de cuatro tratamientos. Las variables de respuesta consistieron en el peso a los días 28,35 y 39 y en el logaritmo del título de Gumboro, Newcastle y Bronquitis infecciosa al día 39. Para el análisis, se hicieron tablas de estadística descriptiva (promedios, desviación estándar y conteo) por replicación y por tratamiento. Se elaboraron modelos lineales mixtos aleatorios en los días 28, 35 y 39 para el peso, teniendo como efecto aleatorio la replicación, y como efectos fijos la adición de propóleos, la inoculación de cepa bacteriana y la interacción entre cepa y propóleos. Se elaboraron modelos lineales mixtos aleatorios para el logaritmo del título de Gumboro, Newcastle y Bronquitis infecciosa, 
teniendo como efecto aleatorio la replicación, y como efectos fijos la adición de propóleos, la inoculación de cepa bacteriana y la interacción entre cepa y propóleos. Todo el procesamiento de datos se realizó utilizando el software $R$ versión 3.0.1 [24] y el programa Microsoft Excel 2007. Las pruebas de hipótesis se evaluaron al nivel de significancia del 5\%.

\section{Resultados}

Los resultados obtenidos de las cuatro muestras de propóleos por medio de la prueba HPLC/DAD muestran que los flavonoides encontrados corresponden a Quercetina, Luteolina, Naringenina, Apigenina, Kaempferol; la muestra de mayor concentración correspondió a la número dos, por lo que fue la utilizada en el experimento (tabla 1).

\section{Resultados del experimento uno}

En cuanto al peso de las aves del experimento uno, se observó que, en la semana uno, el mayor peso promedio fue para el grupo Hembra-propóleos, seguido por los grupos Hembra-control y Propóleos-macho. Los machos tuvieron un peso ligeramente superior en conjunto que las hembras. En la semana dos, nuevamente los machos tuvieron un mayor peso que las hembras; sin embargo, los machos con propóleos tuvieron un peso ligeramente superior a los machos sin propóleos, pero las hembras con propóleos tuvieron un peso ligeramente inferior y fueron menos homogéneas que las hembras control.

En las semanas cuatro y cinco, se mantuvo una tendencia similar a la observada en las semanas dos y tres, es decir, un peso ligeramente superior por parte

Tabla 1. Resultados de cromatografía en muestras de propóleos

\begin{tabular}{|c|c|c|c|c|c|c|}
\hline & \multicolumn{7}{|c|}{ Concentración en (mg/ml) en la muestra } \\
\hline & & & $\mathbf{9 8 3 5 6 6 - 0 1 - E B}$ & $\mathbf{9 8 3 5 6 6 - 0 2 - E B}$ & $\mathbf{9 5 3 8 6 6 - 0 3 - E B}$ & 983566-04-EB EB \\
\hline Compuesto & tR & $\begin{array}{c}\text { NMC } \\
\mathbf{M g} / \mathrm{ml}\end{array}$ & $\begin{array}{c}\text { Muestra 01 } \\
\text { Apis mellifera } \\
\text { Lebrija, Sder }\end{array}$ & $\begin{array}{c}\text { Muestra 02 } \\
\text { Apis mellifera } \\
\text { San Gil, Sder }\end{array}$ & $\begin{array}{c}\text { Muestra 03 } \\
\text { Tetrágona p. } \\
\text { F/blanca, Sder }\end{array}$ & $\begin{array}{c}\text { Muestra 04 } \\
\text { Apis mellifera } \\
\text { Garzón, Huila }\end{array}$ \\
\hline Quercetina & 26,76 & 0,4 & $<0,2$ & 7 & 14 & 8 \\
\hline Luteolina & 27,25 & 0,4 & $<0,2$ & 8 & 13 & 5 \\
\hline Narigenina & 30,37 & 0,5 & 4 & 63 & 12 & 44 \\
\hline Apigenina & 30,60 & 0,5 & 3 & 10 & 6 & 5 \\
\hline Kaempferol & 30.63 & 0,5 & 3 & 15 & & 7 \\
\hline
\end{tabular}

Fuente: Laboratorio de Cromatografía, Universidad Industrial de Santander (UIS), 2012

de los machos, comparado con las hembras, con mayor peso promedio en el grupo propóleos.

$\mathrm{Al}$ momento del sacrificio, los pesos de los grupos machos y hembras fueron similares, y los pesos del grupo propóleos tanto en machos como hembras fueron mayores que el grupo control. El peso promedio en gramos y la desviación estándar para el grupo control en las hembras y machos fue de $2227 \pm 213$ y $2181 \pm 43$ respectivamente, mientras que en el grupo propóleos en las hembras y machos fue de $2275 \pm$ 257,8 y $2294 \pm 233,4$. Se añade que los grupos que recibieron propóleos tuvieron mayor variabilidad (tabla 2, figura 1). 
Tabla 2. Estadística descriptiva del peso (en gramos) de las aves alimentadas con y sin propóleos, en un periodo de seis semanas

\begin{tabular}{|c|c|c|c|c|c|c|c|c|c|}
\hline & & & \multicolumn{7}{|c|}{ Semana } \\
\hline & Sexo & & 0 & 1 & 2 & 3 & 4 & 5 & 6 \\
\hline \multirow{8}{*}{ Sin propóleos } & \multirow{4}{*}{ Hembra } & Promedio & 42,1 & 149,7 & 373,0 & 730,7 & 1228,1 & 1833,3 & 2227,7 \\
\hline & & D.E. & 3,5 & 12,8 & 36,0 & 60,3 & 122,0 & 173,3 & 213,1 \\
\hline & & Suma & 1810 & 6435 & 16040 & 31420 & 51580 & 78830 & 95790 \\
\hline & & $\mathrm{N}$ & 43 & 43 & 43 & 43 & 42 & 43 & 43 \\
\hline & \multirow{4}{*}{ Macho } & Promedio & 41,4 & 147,7 & 362,2 & 740,3 & 1162,5 & 1783,1 & 2181,9 \\
\hline & & D.E. & 2,9 & 14,2 & 42,3 & 65,8 & 134,0 & 198,2 & 228,8 \\
\hline & & Suma & 1782 & 6350 & 15575 & 31835 & 48825 & 74890 & 91640 \\
\hline & & $\mathrm{N}$ & 43 & 43 & 43 & 43 & 42 & 42 & 42 \\
\hline \multirow{8}{*}{ Con propóleos } & \multirow{4}{*}{ Hembra } & Promedio & 42,1 & 151,4 & 350,8 & 701,1 & 1204,5 & 1847,4 & 2275,0 \\
\hline & & D.E. & 3,0 & 15,3 & 37,0 & 74,0 & 134,0 & 209,2 & 257,8 \\
\hline & & Suma & 1770 & 6360 & 14735 & 29445 & 50590 & 77591 & 95550 \\
\hline & & $\mathrm{N}$ & 42 & 42 & 42 & 42 & 42 & 42 & 42 \\
\hline & \multirow{4}{*}{ Macho } & Promedio & 41,1 & 149,8 & 384,6 & 776,9 & 1241,6 & 1896,4 & 2294,9 \\
\hline & & D.E. & 3,0 & 9,6 & 43,4 & 71,1 & 145,6 & 199,0 & 233,6 \\
\hline & & Suma & 1728 & 6290 & 16155 & 32630 & 50905 & 75855 & 91795 \\
\hline & & $\mathrm{N}$ & 42 & 42 & 42 & 42 & 41 & 40 & 40 \\
\hline
\end{tabular}

Fuente: elaboración propia

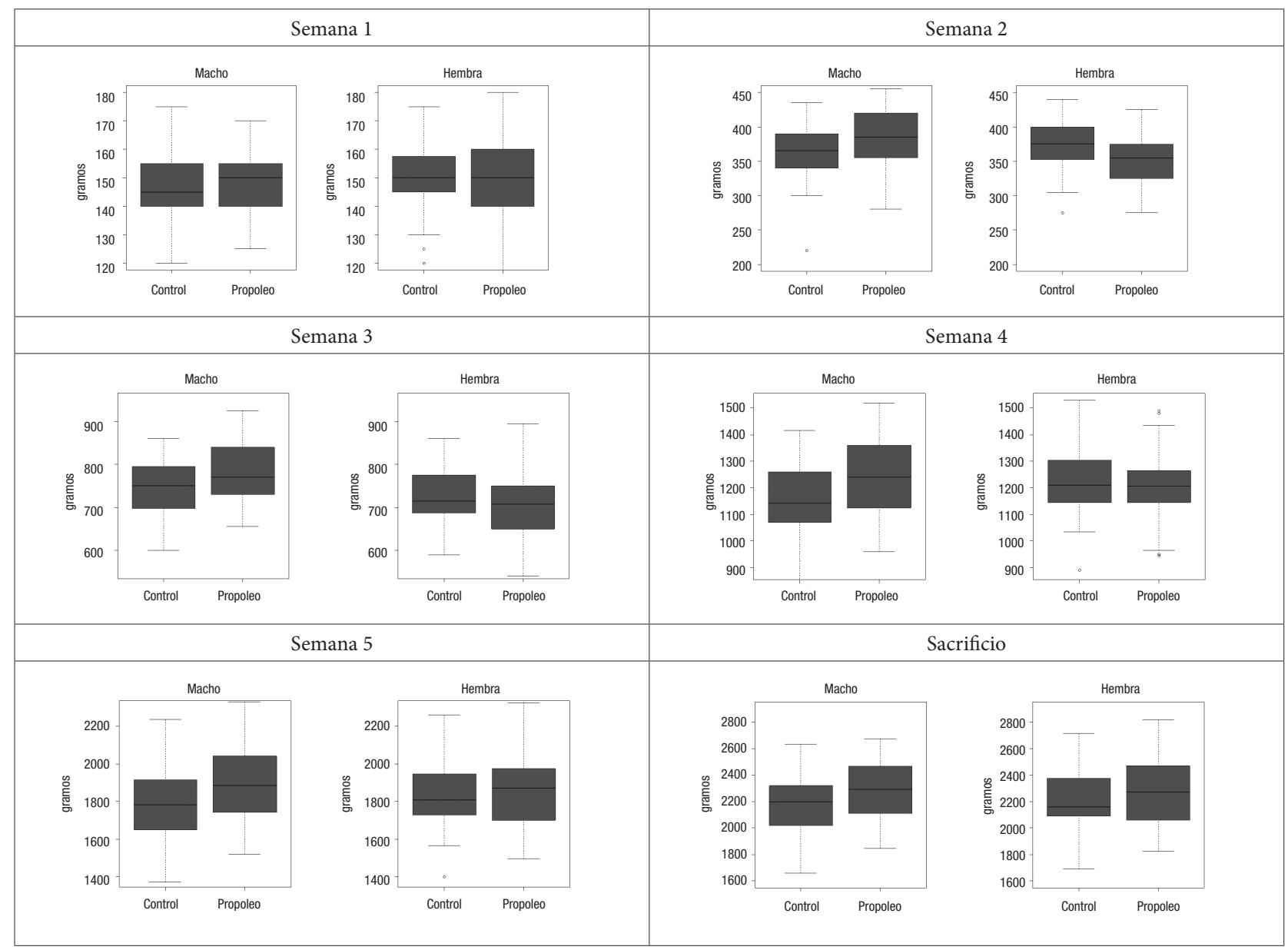

Figura 1. Peso promedio de las aves por semana, para los grupos sin propóleos y con propóleos Fuente: elaboración propia 


\section{Resultados del experimento dos}

En la tabla 3 se presenta la estadística descriptiva del peso de las aves por replicación y tratamiento a los días 28, 35 y 39 de edad. En la replicación uno, se observa que los grupos que recibieron propóleos tuvieron un promedio mayor y una mayor variabilidad que los grupos que no recibieron propóleos. En la replicación dos, en los grupos que no fueron inoculados con la bacteria, el grupo sin propóleos tuvo mayor peso, lo que también ocurrió en los grupos que fueron inoculados con la bacteria.

Tabla 3. Estadística descriptiva del peso de las aves por replicación y por tratamiento, a los días 28, 35 y 39 de edad

\begin{tabular}{|c|c|c|c|c|c|c|c|c|c|c|}
\hline & & \multicolumn{3}{|c|}{ Día 28} & \multicolumn{3}{|c|}{ Día 35} & \multicolumn{3}{|c|}{ Día 39} \\
\hline & Tratamiento & Promedio & D. E. & $\mathrm{n}$ & Promedio & D. E. & $\mathrm{n}$ & Promedio & D. E. & $\mathrm{n}$ \\
\hline \multirow{4}{*}{ Replicación 1} & Con propóleos, sin cepa & 1295 & 77,9 & 5 & 1998 & 63,5 & 5 & 2317 & 362,1 & 5 \\
\hline & Sin propóleos, sin cepa & 1222 & 117,8 & 5 & 1932 & 122,4 & 5 & 2277 & 77,9 & 5 \\
\hline & Con propóleos, con cepa & 1296 & 146,2 & 5 & 1922 & 208,3 & 5 & 2303 & 263,4 & 5 \\
\hline & Sin propóleos, con cepa & 1208 & 98,4 & 5 & 1829 & 133,8 & 5 & 2222 & 163,0 & 5 \\
\hline \multirow{4}{*}{ Replicación 2} & Con propóleos, sin cepa & 1186,3 & 72,9 & 15 & 1667,7 & 198,2 & 15 & 2069,0 & 195,5 & 15 \\
\hline & Sin propóleos, sin cepa & 1218,0 & 130,2 & 15 & 1686,8 & 196,1 & 14 & 2158,8 & 167,3 & 14 \\
\hline & Con propóleos, con cepa & 1195,3 & 133,2 & 15 & 1499,0 & 168,6 & 15 & 1907,0 & 212,5 & 15 \\
\hline & Sin propóleos, con cepa & 1170,7 & 98,5 & 15 & 1621,7 & 187,2 & 15 & 2025,0 & 231,1 & 15 \\
\hline
\end{tabular}

Fuente: elaboración propia

Con respecto al peso promedio por tratamiento a los días 28, 35 y 39, los grupos que no fueron inoculados tuvieron mayor peso promedio que los grupos inoculados con la bacteria, y los grupos con propóleos tuvieron menor peso promedio que los grupos que no recibieron propóleos.
La evolución del peso promedio desde el día 28 al 39 (tabla 4) muestra que el peso fue mayor en todo el periodo para el grupo con propóleos sin inoculación de cepa bacteriana, seguido por el grupo con propóleos sin inoculación de cepa, mientras que el grupo con propóleos con inoculación de cepa bacteriana tuvo el menor peso promedio durante el periodo de estudio (figura 2).

Tabla 4. Estadística descriptiva del peso de las aves por tratamiento, a los días 28, 35 y 39 de vida

\begin{tabular}{|c|c|c|c|c|c|c|c|c|c|}
\hline & \multicolumn{3}{|c|}{ Día 28 } & \multicolumn{3}{c|}{ Día 35 } & \multicolumn{3}{c|}{ Día 39 } \\
\hline Tratamiento & Promedio & D. E. & n & Promedio & D. E. & n & Promedio & D. E. & n \\
\hline Con propóleos, sin cepa & 1213,5 & 86,8 & 20 & 1750,3 & 226,6 & 20 & 2131,0 & 260,6 & 20 \\
\hline Sin propóleos, sin cepa & 1219,0 & 124,2 & 20 & 1751,3 & 208,4 & 19 & 2189,9 & 156,3 & 19 \\
\hline Con propóleos, con cepa & 1220,5 & 139,9 & 20 & 1604,8 & 255,7 & 20 & 2006,0 & 280,8 & 20 \\
\hline Sin propóleos, con cepa & 1180,0 & 97,3 & 20 & 1673,5 & 195,2 & 20 & 2074,3 & 229,4 & 20 \\
\hline
\end{tabular}

Fuente: elaboración propia 


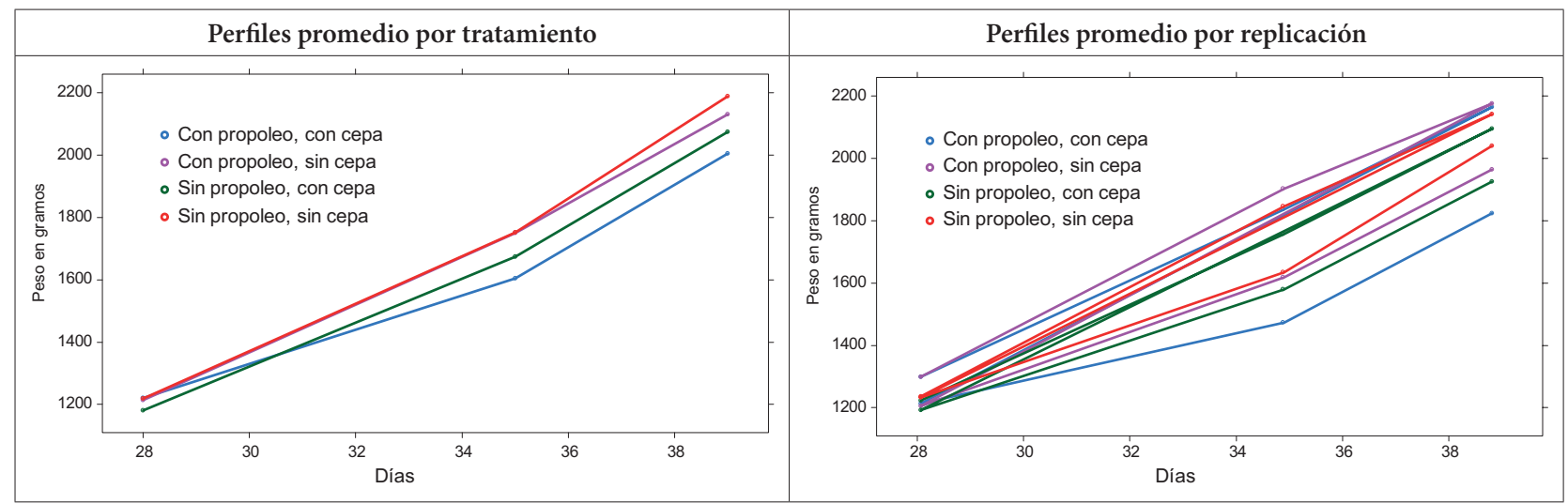

Figura 2. Perfiles longitudinales del peso de las aves en los tratamientos experimentales Fuente: elaboración propia

A continuación se presentan los modelos mixtos lineales para el peso en los días 28,35 y 39 de edad (tablas 5,6 y 7 ).
Utilizando los modelos mixtos lineales, se generan las comparaciones múltiples de promedios de peso entre los tratamientos para los días 28,35 y 39. Al día

Tabla 5. Modelo mixto lineal para el peso al día 28 en los grupos de tratamiento

\begin{tabular}{|c|c|c|c|c|c|}
\hline Efecto & Valor & Error estándar & GL & t-valor & p-valor \\
\hline Con propóleos & 1232,87 & 37,89 & 75 & 32,54 & 0,000 \\
\hline Sin propóleos & 1192,37 & 37,89 & 75 & 31,47 & 0,000 \\
\hline Sin cepa & $-7,00$ & 35,19 & 75 & $-0,19$ & 0,843 \\
\hline Sin propóleos: sin cepa & 46,00 & 49,78 & 75 & 0,92 & 0,358 \\
\hline & $\begin{array}{c}\text { Parámetros de varianza } \\
\text { Intercepto }\end{array}$ & Residual & & & \\
\hline Desviación estándar & 39,38 & 111,30 & & & \\
\hline
\end{tabular}

Fuente: elaboración propia

Tabla 6. Modelo mixto lineal para el peso al día 35 en los grupos de tratamiento

\begin{tabular}{|c|c|c|c|c|c|}
\hline Efecto & Valor & Error estándar & GL & t-valor & p-valor \\
\hline Con propóleos & 1678,41 & 154,76 & 74 & 10,85 & 0,000 \\
\hline Sin propóleos & 145,5 & 56,51 & 74 & 2,57 & 0,012 \\
\hline Sin cepa & 68,75 & 56,51 & 74 & 1,22 & 0,228 \\
\hline Sin propóleos: sin cepa & $-71,56$ & 80,45 & 74 & $-0,89$ & 0,377 \\
\hline \multicolumn{5}{|c|}{ Parámetros de varianza } \\
\hline \multicolumn{7}{|c|}{ Residual } & & & \\
\hline
\end{tabular}

Fuente: elaboración propia 
Tabla 7. Modelo mixto lineal para el peso al día 39 en los grupos de tratamiento

\begin{tabular}{|c|c|c|c|c|c|}
\hline Efecto & Parámetro & Error estándar & GL & t-valor & p-valor \\
\hline Con propóleos & 2062,92 & 127,02 & 74 & 16,24 & 0,000 \\
\hline Sin propóleos & 68,25 & 67,43 & 74 & 1,01 & 0,315 \\
\hline Sin cepa & 125 & 67,43 & 74 & 1,85 & 0,068 \\
\hline Sin propóleos: sin cepa & $-12,35$ & 95,98 & 74 & $-0,13$ & 0,898 \\
\hline & & Parámetros de varianza & & & \\
\hline Desviación estándar & Intercepto & Residual & & & \\
\hline
\end{tabular}

Fuente: elaboración propia

28 , se encontró evidencia estadística de que los promedios de peso entre los grupos de tratamiento eran iguales, al nivel de significancia de 5\%, utilizando el método de Tukey (tabla 8).

Tabla 8. Comparaciones múltiples utilizando el método de Tukey, para el peso en el día 28

\begin{tabular}{|c|c|c|c|c|}
\hline & Estimado & Error estándar & Estadístico $\mathbf{z}$ & $\operatorname{Pr}(>|\mathrm{z}|)$ \\
\hline SPSC - CPSC & 5,5 & 35,2 & 0,156 & 0,999 \\
\hline SPCC - CPSC & $-33,5$ & 35,2 & $-0,952$ & 0,777 \\
\hline SPCC - CPSC & 7 & 35,2 & 0,199 & 0,997 \\
\hline SPCC - CPSC & -39 & 35,2 & $-1,108$ & 0,685 \\
\hline SPCC - CPSC & 1,5 & 35,2 & 0,043 & 1 \\
\hline SPCC - CPSC & 40,5 & 35,2 & 1,151 & 0,658 \\
\hline
\end{tabular}

SPSC: sin propóleos sin cepa; SPCC: sin propóleos con cepa; CPSC: con propóleos sin cepa; CPCC: con propóleos con cepa

Fuente: elaboración propia

Al día 35, se encontró evidencia estadística de que los promedios de peso son iguales entre los grupos de tratamiento, utilizando el método de Tukey (tabla 9), con excepción de la comparación entre los grupos con propóleos con y sin cepa.

Tabla 9. Comparaciones múltiples utilizando el método de Tukey para el peso en el día 35

\begin{tabular}{|l|c|c|c|c|}
\hline & Estimado & Error estándar & Estadístico z & $\operatorname{Pr}(>|\mathrm{z}|)$ \\
\hline SPSC - CPSC & $-2,811$ & 57,255 & $-0,049$ & 1 \\
\hline SPSC - CPSC & $-76,75$ & 56,513 & $-1,358$ & 0,5258 \\
\hline SPSC - CPSC & $-145,5$ & 56,513 & $-2,575$ & 0,0488 \\
\hline SPSC - CPSC & $-73,939$ & 57,255 & $-1,291$ & 0,5684 \\
\hline SPSC - CPSC & $-142,689$ & 57,255 & $-2,492$ & 0,0613 \\
\hline SPSC - CPSC & $-68,75$ & 56,513 & $-1,217$ & 0,6163 \\
\hline
\end{tabular}

Fuente: elaboración propia
Al día 39, se encontró evidencia estadística de diferencia en los promedios de peso entre los grupos de tratamiento CPCC - SPSC, utilizando el método de Tukey (tabla 10).

Tabla 10. Comparaciones múltiples utilizando el método de Tukey para el peso en el día 39

\begin{tabular}{|c|c|c|c|c|}
\hline Comparación & Estimado & Error estándar & Estadístico z & $\operatorname{Pr}(>|\mathrm{z}|)$ \\
\hline SPSC - CPSC & 55,9 & 68,31 & 0,818 & 0,8458 \\
\hline SPSC - CPSC & $-56,75$ & 67,43 & $-0,842$ & 0,8345 \\
\hline SPSC - CPSC & -125 & 67,43 & $-1,854$ & 0,2482 \\
\hline SPSC - CPSC & $-112,65$ & 68,31 & $-1,649$ & 0,3511 \\
\hline SPSC - CPSC & $-180,9$ & 68,31 & $-2,648$ & 0,0402 \\
\hline SPSC - CPSC & $-68,25$ & 67,43 & $-1,012$ & 0,7423 \\
\hline
\end{tabular}

Fuente: elaboración propia 


\section{Consumo promedio}

El consumo del alimento por ave se programó de acuerdo con la tabla de la línea genética Ross, en la que todas las aves recibieron la misma cantidad de alimento por día, y se obtuvo un consumo promedio por ave de 3850 g durante los cuarenta días del experimento (figura 3, tabla 11).

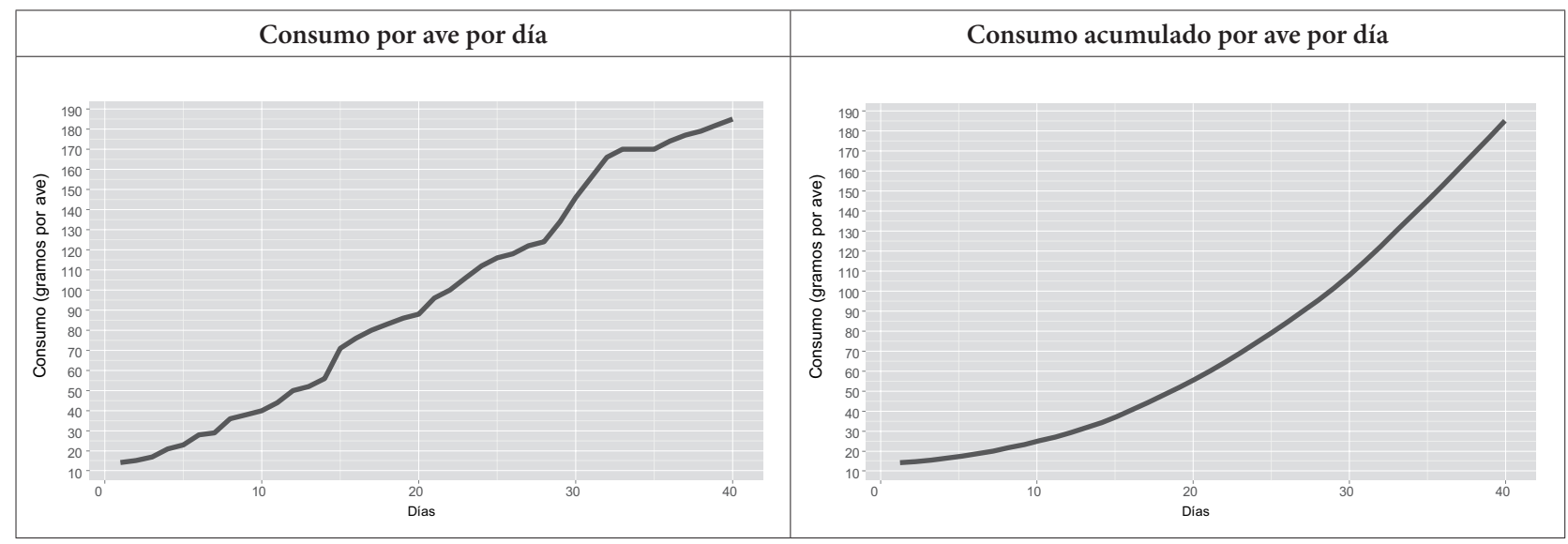

Figura 3. Consumo diario y acumulado por ave por día en los grupos experimentales

Tabla 11. Consumo diario y acumulado por ave, en un periodo de cuarenta días, para todas las aves

\begin{tabular}{|l|l|l|l|l|l|l|}
\hline & \multicolumn{7}{|c|}{ Día } \\
\hline Consumo & 7 & 14 & 21 & 28 & 35 & 40 \\
\hline En el día $(\mathrm{g})$ & 29 & 56 & 96 & 124 & 170 & 185 \\
\hline Acumulado $(\mathrm{g})$ & 147 & 463 & 1043 & 1841 & 2953 & 3850 \\
\hline
\end{tabular}

Fuente: elaboración propia

\section{Conversión alimenticia}

Con respecto a la conversión alimenticia (tabla 12), se observa que al momento del sacrificio, la menor conversión es para el grupo Macho-propóleos, seguido por el grupo Hembra-propóleos.

Tabla 12. Conversión acumulada semanal y final por tratamiento

\begin{tabular}{|c|c|c|c|c|c|c|}
\hline & & \multicolumn{5}{|c|}{ Semana } \\
\hline Tratamiento & Sexo & 2 & 3 & 4 & 5 & Sacrificio \\
\hline \multirow{3}{*}{ Control } & Hembra & 1,24 & 1,43 & 1,50 & 1,61 & 1,73 \\
\cline { 2 - 7 } & Macho & 1,28 & 1,41 & 1,58 & 1,66 & 1,76 \\
\hline \multirow{2}{*}{ Propóleos } & Hembra & 1,32 & 1,49 & 1,53 & 1,60 & 1,69 \\
\cline { 2 - 7 } & Macho & 1,20 & 1,34 & 1,48 & 1,56 & 1,68 \\
\hline
\end{tabular}

Con respecto a la conversión a los días 28,35 y 39 (tabla 13), en la replicación 1, la conversión fue menor en el grupo sin propóleos sin inoculación de cepa bacteriana, seguido por el grupo con propóleos con inoculación de cepa bacteriana. En la replicación 2, los grupos sin inoculación de cepa bacteriana tuvieron menor conversión que los grupos con inoculación de cepa bacteriana. Nuevamente, el grupo sin propóleos sin inoculación de cepa bacteriana tuvo una mejor conversión, seguido por el grupo con propóleos sin inoculación.

Tabla 13. Conversión alimenticia a los días 28, 35 y 39, por replicación, entre grupos de tratamiento

\begin{tabular}{|c|c|c|c|c|}
\hline & & \multicolumn{3}{|c|}{ Día } \\
\hline \multirow{4}{*}{ Replicación 1 } & Tratamiento & 28 & 35 & 39 \\
\cline { 2 - 5 } & Con propóleos, sin cepa & 1,43 & 1,48 & 1,62 \\
\cline { 2 - 5 } & Sin propóleos, sin cepa & 1,52 & 1,53 & 1,61 \\
\cline { 2 - 5 } & Con propóleos, con cepa & 1,43 & 1,55 & 1,61 \\
\cline { 2 - 5 } & Sin propóleos, con cepa & 1,53 & 1,62 & 1,66 \\
\hline \multirow{3}{*}{ Replicación 2 } & Sin propóleos, sin cepa & 1,53 & 1,78 & 1,71 \\
\cline { 2 - 5 } & Con propóleos, con cepa & 1,56 & 1,99 & 1,94 \\
\cline { 2 - 5 } & Con propóleos, sin cepa & 1,56 & 1,80 & 1,79 \\
\cline { 2 - 5 } & Sin propóleos, con cepa & 1,58 & 1,84 & 1,83 \\
\hline
\end{tabular}

Fuente: elaboración propia

Si se observa la conversión por tratamiento a los días 28, 35 y 39 (tabla 14), se puede encontrar que la menor conversión fue para el grupo con propóleos sin inoculación de cepa bacteriana, y la mayor conversión fue para el grupo con propóleos con inoculación de cepa. 
Tabla 14. Promedio de la conversión de las aves por tratamiento a los días 28,35 y 39

\begin{tabular}{|c|c|c|c|}
\hline & \multicolumn{3}{|c|}{ Día } \\
\hline Tratamiento & 28 & 35 & 39 \\
\hline Con propóleos, sin cepa & 1,52 & 1,72 & 1,74 \\
\hline Sin propóleos, sin cepa & 1,53 & 1,71 & 1,68 \\
\hline Con propóleos, con cepa & 1,53 & 1,88 & 1,86 \\
\hline Sin propóleos, con cepa & 1,57 & 1,79 & 1,79 \\
\hline
\end{tabular}

Fuente: elaboración propia

\section{Mortalidad}

En la tabla 15, se puede apreciar el número de aves que murieron durante todo el experimento de acuerdo con la semana y con referencia a los diferentes tratamientos con y sin suministro de propóleos en el agua de consumo.

Tabla 15. Mortalidad de las aves experimentales

\begin{tabular}{|c|c|c|c|c|c|c|c|c|c|}
\hline \multirow{2}{*}{ Semanas } & \multicolumn{3}{|c|}{ T1 con propóleos } & \multicolumn{5}{c|}{ T2 sin propóleos } & $\begin{array}{c}\text { Total } \\
\text { aves }\end{array}$ \\
\hline & Jaula 1 & Jaula 2 & Jaula 3 & Jaula 4 & Jaula 1 & Jaula 2 & Jaula 3 & Jaula 4 & \\
\hline 1 & & & & 1 & & & & & 1 \\
\hline 2 & 1 & 1 & & & & 1 & & & 3 \\
\hline 3 & & & & & & & & & \\
\hline 4 & & & & & & & & & \\
\hline 5 & & & & & & 1 & & & 1 \\
\hline 6 & & & & & & & & 1 & 1 \\
\hline $\begin{array}{c}\text { Total } \\
\text { aves }\end{array}$ & 1 & 1 & & 1 & & 2 & & 1 & 6 \\
\hline
\end{tabular}

Fuente: elaboración propia

Durante todo el experimento se presentó una mortalidad de 6 aves en total, y se obtuvo un porcentaje del 2,34\% de mortalidad sobre el total de aves experimentales, porcentaje normal que nos muestra que no hubo diferencia en el número de aves muertas, pero sí en la edad en que ocurrió la muerte.

De la mortalidad ocurrida en las aves que consumieron propóleos (T1), se muestra una ave muerta al cuarto día de la jaula número cuatro, cuya causa fue onfalitis; esta enfermedad es debida a problemas de incubación. En la segunda semana, las aves que consumieron propóleos (T1) presentaron dos aves muertas, una al día diez, jaula número dos, cuyo diagnóstico fue por infarto coronario y al día doce, jaula número uno, por edema aviar. Las aves que no consumieron propóleos (T2) en esta semana presentaron una ave muerta al día trece, jaula número dos, y el diagnóstico fue también edema aviar. En la semana quinta, a los 34 días de vida, en la jaula número dos de las aves testigo (T2), hubo una muerte por causa de edema aviar y al día 36, sexta semana, una ave muerta de la jaula cuatro, por infarto (tabla 16).

Tabla 16. Diagnóstico de las aves muertas

\begin{tabular}{|c|c|c|c|}
\hline Fecha & Tratamiento & Diagnóstico & Edad muerte (días) \\
\hline Abril 16 & $\mathrm{~T} 1$ & Onfalitis & 4 \\
\hline Abril 21 & $\mathrm{T} 1$ & Infarto & 10 \\
\hline Abril 23 & $\mathrm{T} 1$ & Edema aviar & 12 \\
\hline Abril 24 & $\mathrm{T} 2$ & Edema aviar & 13 \\
\hline Mayo 15 & $\mathrm{T} 2$ & Edema aviar & 34 \\
\hline Mayo 17 & $\mathrm{T} 2$ & Infarto & 36 \\
\hline
\end{tabular}

Fuente: elaboración propia

La onfalitis es una contaminación bacteriana sufrida por las aves, generalmente durante el proceso de incubación.

El edema aviar es un síndrome cuya etiología tiene diversas causas, especialmente, diferencias en los cambios bruscos de la temperatura ambiental, sufridos por todas las aves experimentales [25].

No se observó, en las aves muertas, sintomatología compatible con colibacilosis, ni en las aves testigos ni en las aves inoculadas.

\section{Resultado de análisis de laboratorio}

Para la toma de muestras se sacrificaron 20 animales. Los cultivos y antibiogramas que fueron realizados en el laboratorio dieron los resultados mostrados en la tabla 17. 
Tabla 17. Resultados de cultivos de órganos (hígado, pulmón, tráquea) en aves experimentales

\begin{tabular}{|c|c|c|c|c|c|c|}
\hline Experimento & Replicación & Tratamiento & Escherichia coli & Psudomona aeruginosa & Proteus vulgaris & Proteus mirabilis \\
\hline \multirow{2}{*}{1} & & CPSC & $\mathrm{x}$ & & & \\
\hline & & SPSC & $\mathrm{x}$ & & & \\
\hline \multirow{8}{*}{2} & 1 & CPSC & $\mathrm{x}$ & & & \\
\hline & 2 & CPSC & $\mathrm{x}$ & & & \\
\hline & 1 & SPSC & $\mathrm{x}$ & $\mathrm{x}$ & & \\
\hline & 2 & SPSC & $\mathrm{x}$ & & & \\
\hline & 1 & SPCC & $\mathrm{x}$ & & & \\
\hline & 2 & SPCC & $\mathrm{x}$ & & $\mathrm{x}$ & \\
\hline & 1 & CPCC & $\mathrm{x}$ & & & \\
\hline & 2 & CPCC & $\mathrm{x}$ & & & $\mathrm{x}$ \\
\hline
\end{tabular}

Fuente: elaboración propia

En todas las aves experimentales se aisló E. coli, sin poder diferenciar si fue la cepa inoculada o la bacteria normal de las aves, ninguna ave presentó sintomatología clínica de esta enfermedad (tabla 17).
Para este análisis, se realizó la prueba de susceptibilidad antimicrobiana en microorganismos aeróbicos por el método de agar Mueller Hinton, y se obtuvieron los resultados mostrados en la tabla 18.

Tabla 18. Resultado de antibiogramas del aislamiento de la bacteria E. coli

\begin{tabular}{|c|c|c|c|c|c|c|c|c|c|c|c|c|}
\hline Tratamiento & F & C & Le & E & No & G & Ne & T-s & Li & D & O \\
\hline T1 & s & sm & sm & sm & sm & r & r & r & r & r & r \\
\hline T2 & $\mathrm{s}$ & $\mathrm{s}$ & $\mathrm{s}$ & $\mathrm{s}$ & $\mathrm{sm}$ & $\mathrm{sm}$ & $\mathrm{sm}$ & $\mathrm{sm}$ & $\mathrm{r}$ & $\mathrm{r}$ & $\mathrm{r}$ \\
\hline T3 & $\mathrm{s}$ & $\mathrm{s}$ & $\mathrm{sm}$ & $\mathrm{s}$ & $\mathrm{s}$ & $\mathrm{r}$ & $\mathrm{s}$ & $\mathrm{r}$ & $\mathrm{r}$ & $\mathrm{r}$ & $\mathrm{r}$ \\
\hline T4 & $\mathrm{s}$ & $\mathrm{sm}$ & $\mathrm{sm}$ & $\mathrm{r}$ & $\mathrm{sm}$ & $\mathrm{r}$ & $\mathrm{s}$ & $\mathrm{r}$ & $\mathrm{r}$ & $\mathrm{r}$ & $\mathrm{r}$ \\
\hline T5 & $\mathrm{s}$ & $\mathrm{s}$ & $\mathrm{s}$ & $\mathrm{s}$ & $\mathrm{sm}$ & $\mathrm{sm}$ & $\mathrm{sm}$ & $\mathrm{sm}$ & $\mathrm{r}$ & $\mathrm{r}$ & $\mathrm{r}$ \\
\hline T6 & $\mathrm{s}$ & $\mathrm{s}$ & $\mathrm{sm}$ & $\mathrm{sm}$ & $\mathrm{sm}$ & $\mathrm{r}$ & $\mathrm{r}$ & $\mathrm{r}$ & $\mathrm{r}$ & $\mathrm{r}$ & $\mathrm{r}$ \\
\hline T7 & $\mathrm{s}$ & $\mathrm{r}$ & $\mathrm{r}$ & $\mathrm{r}$ & $\mathrm{r}$ & $\mathrm{r}$ & $\mathrm{sm}$ & $\mathrm{r}$ & $\mathrm{r}$ & $\mathrm{r}$ & $\mathrm{r}$ \\
\hline T8 & $\mathrm{sm}$ & $\mathrm{r}$ & $\mathrm{r}$ & $\mathrm{r}$ & $\mathrm{r}$ & $\mathrm{r}$ & $\mathrm{r}$ & $\mathrm{r}$ & $\mathrm{r}$ & $\mathrm{r}$ & $\mathrm{r}$ \\
\hline T9 & $\mathrm{s}$ & $\mathrm{s}$ & $\mathrm{s}$ & $\mathrm{s}$ & $\mathrm{s}$ & $\mathrm{sm}$ & $\mathrm{s}$ & $\mathrm{sm}$ & $\mathrm{r}$ & $\mathrm{r}$ & $\mathrm{r}$ \\
\hline T10 & $\mathrm{s}$ & $\mathrm{s}$ & $\mathrm{sm}$ & $\mathrm{sm}$ & $\mathrm{sm}$ & $\mathrm{r}$ & $\mathrm{r}$ & $\mathrm{r}$ & $\mathrm{r}$ & $\mathrm{r}$ & $\mathrm{r}$ \\
\hline
\end{tabular}

Antibióticos: F: Fosfomicina; C: Ciprofloxacina; Le: Levofloxanin; E: Enrofloxacina; No: Norfloxacin; G: Gentamicina; Ne: Neomicina; T-s: Trimetoprim-sulfa; Li: Lincomicina; D: Doxiciclina; O: Oxitetraciclina. Sensibilidad: s: sensible; sm: sensibilidad intermedia; r: resistente Fuente: elaboración propia

En la tabla 18, los tratamientos corresponden a los descritos en la tabla 19, y las letras mayúsculas corresponden a los antibióticos a que fueron expuestos y las letras minúsculas corresponden a la respuesta sensible a cada uno.

Las aves que consumieron propóleos dieron una sensibilidad marcada a la Fosfomicina y una sensibilidad intermedia a la Ciprofloxacina, Levofloxacina, Enrofloxacina y Norfloxacina. Las que no consumieron propóleos dieron una sensibilidad marcada a la Fosfomicina, Ciprofloxacina, Levofloxacina y Enrofloxacina, y una sensibilidad intermedia a la Norfloxacina, Neomiciana Gentamicina y Trimetoprim-sulfa, lo que nos muestra una mayor gama de antibióticos que pueden actuar sobre la cepa de E. coli presente, aunque como se describió anteriormente la cepa no muestra sintomatología clínica en la aves.

Al comparar el tratamiento T3 con el T5, se observa la misma tendencia del primer grupo, donde existe un mayor número de antibióticos probados con sensibilidad plena e intermedia en el grupo de aves que no consumieron propóleos. 
Tabla 19. Resultado de antibiogramas del aislamiento de bacterias Pseudomona aureginosas, Proteus vulgaris y Proteus mirabilis

\begin{tabular}{|l|c|c|c|c|c|c|c|c|c|c|c|}
\hline \multicolumn{1}{|c|}{ Tratamiento } & $\mathrm{F}$ & $\mathrm{C}$ & $\mathrm{Le}$ & $\mathrm{E}$ & $\mathrm{No}$ & $\mathrm{G}$ & $\mathrm{Ne}$ & $\mathrm{T}-\mathrm{s}$ & $\mathrm{Li}$ & $\mathrm{D}$ & $\mathrm{O}$ \\
\hline T5 Pseudomona aureginosas & $\mathrm{sm}$ & $\mathrm{r}$ & $\mathrm{r}$ & $\mathrm{r}$ & $\mathrm{r}$ & $\mathrm{r}$ & $\mathrm{r}$ & $\mathrm{r}$ & $\mathrm{r}$ & $\mathrm{r}$ & $\mathrm{r}$ \\
\hline T8 Proteus vulgaris & $\mathrm{s}$ & $\mathrm{sm}$ & $\mathrm{sm}$ & $\mathrm{sm}$ & $\mathrm{sm}$ & $\mathrm{r}$ & $\mathrm{r}$ & $\mathrm{r}$ & $\mathrm{r}$ & $\mathrm{r}$ & $\mathrm{r}$ \\
\hline T10 Proteus mirabilis & $\mathrm{s}$ & $\mathrm{s}$ & $\mathrm{s}$ & $\mathrm{s}$ & $\mathrm{s}$ & $\mathrm{r}$ & $\mathrm{s}$ & $\mathrm{sm}$ & $\mathrm{r}$ & $\mathrm{r}$ & $\mathrm{r}$ \\
\hline
\end{tabular}

Fuente: elaboración propia

En el tratamiento T5, se aisló la bacteria Pseudomona aureginosas, en el tratamiento T8 Proteus vulgaris y en el T10 Proteus mirabilis, además de la bacteria Escherichia coli, y su sensibilidad está descrita en la tabla 19.

\section{Resultados comparativos de anticuerpos de Gumboro, Newcastle y Bronquitis}

Se presentan los resultados del logaritmo del título de Gumboro, Bronquitis y Newcastle por replicación y por tratamiento (tabla 20 y figura 4). En la replicación 1, en relación con el Gumboro, el tratamiento con propóleos sin inoculación de cepa bacteriana tuvo el mayor título promedio, y el de menor título fue el tratamiento con propóleos y con inoculación de cepa bacteriana. En la replicación 2, el tratamiento sin propóleos sin inoculación tuvo el mayor título promedio, mientras que el menor título se dio en el grupo con propóleos sin inoculación de cepa bacteriana. En relación con los títulos de Newcastle, en la replicación 1, el tratamiento con propóleos sin inoculación de cepa bacteriana tuvo mayores títulos, mientras que en la replicación 2, los cuatro tratamientos tuvieron títulos similares. Con respecto a los títulos de Bronquitis, los grupos con y sin propóleos y con inoculación de cepa bacteriana tuvieron títulos más altos que los grupos con y sin propóleos y sin inoculación de cepa bacteriana, en las replicaciones 1 y 2 .

Tabla 20. Estadística descriptiva del logaritmo del título de Gumboro, Bronquitis y Newcastle, al día 38

\begin{tabular}{|c|c|c|c|c|c|c|c|c|c|c|}
\hline & & \multicolumn{3}{|c|}{ Gumboro } & \multicolumn{3}{|c|}{ Bronquitis } & \multicolumn{3}{|c|}{ Newcastle } \\
\hline & Tratamiento & Promedio & D. E. & $\mathbf{n}$ & Promedio & D. E. & $\mathbf{n}$ & Promedio & D. E. & $\mathbf{n}$ \\
\hline \multirow{4}{*}{ Replicación 1} & Con propóleos, sin cepa & 3,77968 & 0,09563 & 15 & 3,5795 & 0,1346 & 15 & 3,6486 & 0,0894 & 15 \\
\hline & Sin propóleos, sin cepa & 3,43883 & 0,21977 & 15 & 3,4269 & 0,2593 & 15 & 3,3871 & 0,1832 & 15 \\
\hline & Con propóleos, con cepa & 3,40208 & 0,06382 & 3 & 3,9011 & 0,1111 & 3 & 3,3889 & 0,104 & 3 \\
\hline & Sin propóleos, con cepa & 3,55518 & 0,12854 & 4 & 3,9559 & 0,0933 & 4 & 3,496 & 0,1223 & 4 \\
\hline \multirow{4}{*}{ Replicación 2} & Con propóleos, sin cepa & 3,51516 & 0,17329 & 8 & 3,7923 & 0,1249 & 8 & 3,6275 & 0,1348 & 8 \\
\hline & Sin propóleos, sin cepa & 3,60829 & 0,11699 & 8 & 3,7153 & 0,1838 & 8 & 3,5654 & 0,1899 & 8 \\
\hline & Con propóleos, con cepa & 3,47896 & 0,18608 & 4 & 3,9899 & & 1 & 3,6836 & & 1 \\
\hline & Sin propóleos, con cepa & 3,51949 & 0,07959 & 3 & 4,0918 & 0,0805 & 3 & 3,5012 & 0,266 & 3 \\
\hline
\end{tabular}

Fuente: elaboración propia

En la figura 5 y la tabla 21, se encuentra la estadística descriptiva de los títulos de Gumboro, Newcastle y Bronquitis por tratamiento. En relación con el Gumboro, el tratamiento con propóleos sin inoculación de cepa bacteriana tuvo un mayor promedio que los otros grupos. El grupo con propóleos con inoculación de cepa bacteriana presentó menores títulos que los otros grupos. Para el Newcastle, el tratamiento con mayor título también fue el grupo con propóleos sin inoculación de cepa, y los otros tres tratamientos tuvieron títulos similares, aunque el grupo sin propóleos sin cepa tuvo una mayor variabilidad. Finalmente, para la Bronquitis infecciosa, los grupos con propóleos y sin propóleos que fueron inoculados con cepa bacteriana tuvieron títulos superiores a los tratamientos sin inoculación con cepa bacteriana. 


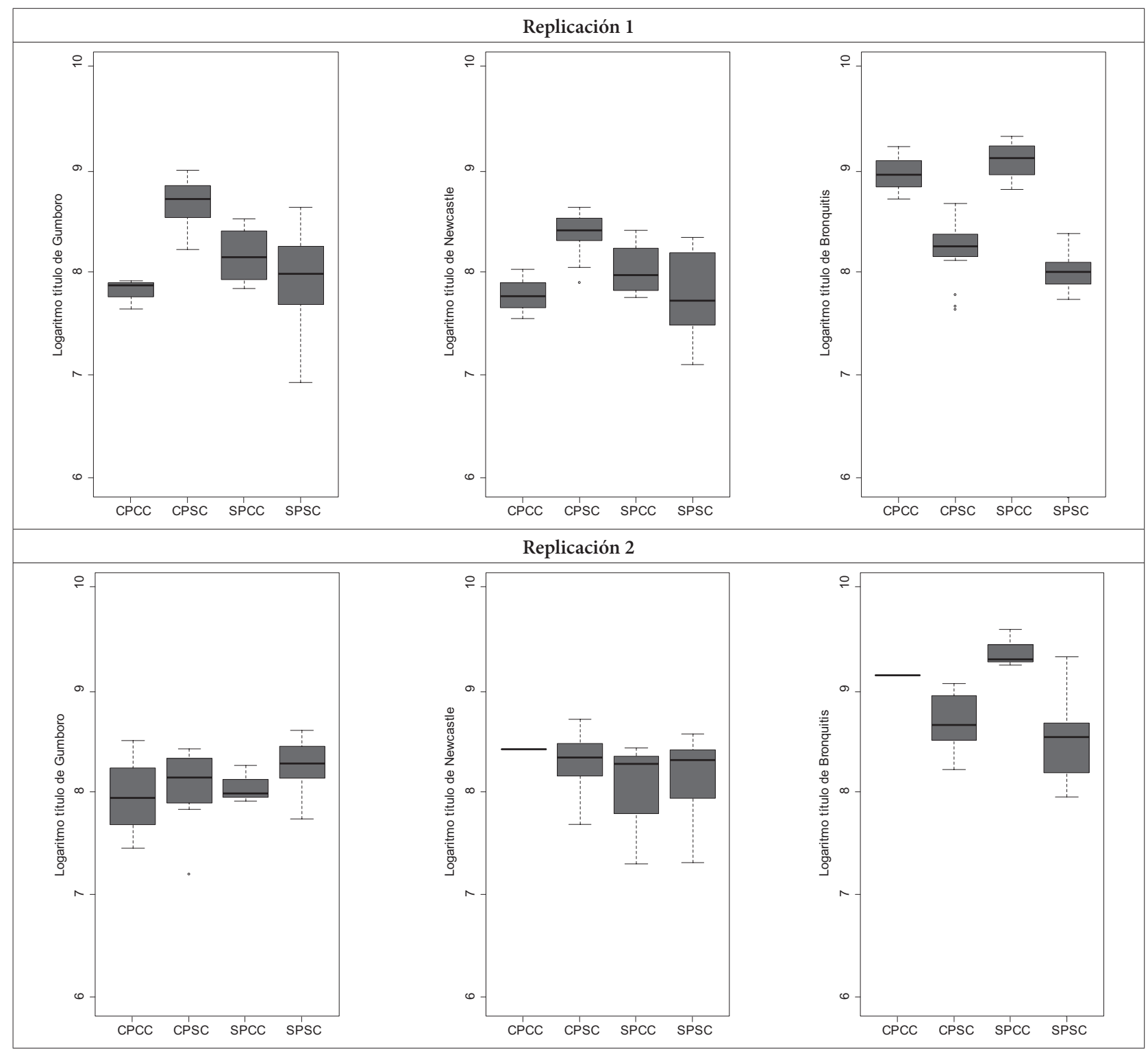

Figura 4. Diagrama de cajas para el logaritmo del título de Gumboro, Newcastle y Bronquitis, de acuerdo con la replicación y el tratamiento. CPCC (con propóleos con cepa), CPSC (con propóleos sin cepa), sPCC (sin propóleos con cepa), sPSC (sin propóleos sin cepa) Fuente: elaboración propia 


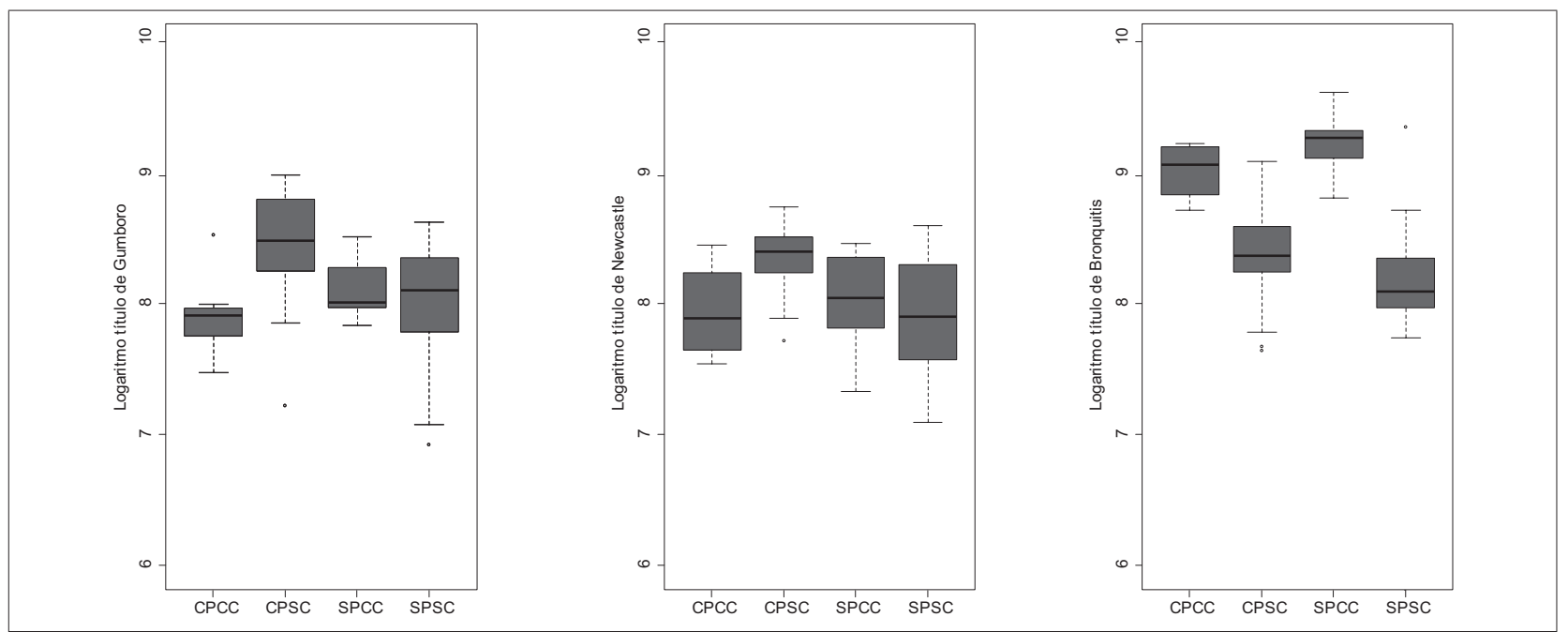

Figura 5. Diagrama de cajas para el logaritmo del título de Gumboro, Newcastle y Bronquitis, de acuerdo con el tratamiento. CPCC (con propóleos con cepa), CPSC (con propóleos sin cepa), sPCC (sin propóleos con cepa), sPSC (sin propóleos sin cepa)

Fuente: elaboración propia

Tabla 21. Estadística descriptiva del logaritmo del título de Gumboro, Bronquitis y Newcastle

\begin{tabular}{|c|c|c|c|c|c|c|c|c|c|}
\hline & \multicolumn{3}{|c|}{ Gumboro } & \multicolumn{3}{c|}{ Bronquitis } & \multicolumn{3}{c|}{ Newcastle } \\
\hline Tratamiento & Promedio & D. E. & n & Promedio & D. E. & n & Promedio & D. E. & n \\
\hline Con propóleos, sin cepa & 3,6877 & 0,1788 & 23 & 3,6535 & 0,1650 & 23 & 3,6413 & 0,1048 & 23 \\
\hline Sin propóleos, sin cepa & 3,4978 & 0,2047 & 23 & 3,5272 & 0,2706 & 23 & 3,4491 & 0,2009 & 23 \\
\hline Con propóleos, con cepa & 3,4460 & 0,1427 & 7 & 3,9233 & 0,1010 & 4 & 3,4626 & 0,1700 & 4 \\
\hline Sin propóleos, con cepa & 3,5399 & 0,1036 & 7 & 4,0141 & 0,1086 & 7 & 3,4982 & 0,1763 & 7 \\
\hline
\end{tabular}

Fuente: elaboración propia

Con respecto a la estadística inferencial para el logaritmo del título de Gumboro, Newcastle y Bronquitis, en las tablas 22, 23, 24, se presentan los modelos mixtos lineales para el logaritmo del título serológico, utilizados para elaborar las comparaciones múltiples del título serológico entre los grupos de tratamiento por el método de Tukey.

Tabla 22. Modelo mixto lineal para el logaritmo del título de Gumboro

\begin{tabular}{|c|c|c|c|c|c|}
\hline Efecto & Valor & Error estándar & GL & t-valor & p-valor \\
\hline Con propóleos & 7,93 & 0,157 & 55 & 50,69 & 0,0000 \\
\hline Sin propóleos & 8,15 & 0,157 & 55 & 52,07 & 0,0000 \\
\hline Sin cepa & 0,56 & 0,179 & 55 & 3,11 & 0,0029 \\
\hline Sin propóleos: sin cepa & $-0,65$ & 0,253 & 55 & $-2,58$ & 0,0124 \\
\hline & Intercepto & Residual & & & \\
\hline Desviación estándar & $1,36 \mathrm{E}-05$ & 0,4142 & & & \\
\hline
\end{tabular}

Fuente: elaboración propia
Tabla 23. Modelo mixto lineal para el logaritmo del título de Newcastle

\begin{tabular}{|c|c|c|c|c|c|}
\hline Efecto & Valor & Error estándar & GL & t-valor & p-valor \\
\hline Con propóleos & 8,0059 & 0,2006 & 52 & 39,918 & 0,000 \\
\hline Sin propóleos & 8,0644 & 0,1594 & 52 & 50,590 & 0,000 \\
\hline Sin cepa & 0,3985 & 0,1987 & 52 & 2,005 & 0,050 \\
\hline $\begin{array}{c}\text { Sin propóleos: sin } \\
\text { cepa }\end{array}$ & $-0,5011$ & 0,2543 & 52 & $-1,970$ & 0,054 \\
\hline \multicolumn{5}{|c|}{ Parámetros de varianza } \\
\hline $\begin{array}{c}\text { Desviación } \\
\text { estándar }\end{array}$ & 0,1112064 & 0,3665118 & & & \\
\hline
\end{tabular}

Fuente: elaboración propia 
Tabla 24. Modelo mixto lineal para el logaritmo del título de Bronquitis

\begin{tabular}{|c|c|c|c|c|c|}
\hline Efecto & Parámetro & Error estándar & GL & t-valor & p-valor \\
\hline Con propóleos & 9,157 & 0,328 & 52 & 27,955 & 0,000 \\
\hline Sin propóleos & 9,278 & 0,298 & 52 & 31,182 & 0,000 \\
\hline Sin cepa & $-0,670$ & 0,223 & 52 & $-3,007$ & 0,004 \\
\hline Sin propóleos: sin cepa & $-0,412$ & 0,285 & 52 & $-1,444$ & 0,155 \\
\hline & Parámetros de varianza & & & & \\
\hline Desviación estándar & Intercepto & Residual & & & \\
\end{tabular}

Fuente: elaboración propia

Se encuentra evidencia estadística de que para el Gumboro hubo diferencia en el promedio de logaritmo del título de Gumboro entre los tratamientos sin propóleos sin inoculación de cepa bacteriana y con propóleos sin inoculación de cepa bacteriana, y entre los tratamientos con propóleos con inoculación de cepa bacteriana y con propóleos sin inoculación de cepa bacteriana, teniendo para ambas comparaciones un título mayor el tratamiento con propóleos sin inoculación de cepa bacteriana, al nivel de significancia de 5\% (tabla 25).

Tabla 25. Comparaciones múltiples con el método de Tukey, para el logaritmo del título de Gumboro

\begin{tabular}{|l|c|c|c|c|}
\hline & Estimado & Error estándar & valor $\mathbf{z}$ & $\operatorname{Pr}(>|\mathbf{z}|)$ \\
\hline SPSC - CPSC & $-0,437$ & 0,122 & $-3,580$ & 0,002 \\
\hline SPCC - CPSC & $-0,340$ & 0,179 & $-1,903$ & 0,219 \\
\hline CPCC - CPSC & $-0,556$ & 0,179 & $-3,113$ & 0,010 \\
\hline SPCC - SPSC & 0,097 & 0,179 & 0,542 & 0,947 \\
\hline CPCC - SPSC & $-0,119$ & 0,179 & $-0,667$ & 0,907 \\
\hline CPCC - SPCC & $-0,216$ & 0,221 & $-0,976$ & 0,756 \\
\hline
\end{tabular}

Fuente: elaboración propia

Se encuentra evidencia estadística de que, para el Newcastle, sólo hubo diferencia en el promedio de logaritmo del título de Gumboro entre los tratamientos sin propóleos sin inoculación de cepa bacteriana y con propóleos sin inoculación de cepa bacteriana con un título mayor para el segundo tratamiento, al nivel de significancia de 5\% (tabla 26).
Tabla 26. Comparaciones múltiples con el método de Tukey, para el título de Newcastle

\begin{tabular}{|c|c|c|c|c|}
\hline & Estimado & Error estándar & valor $\mathbf{z}$ & $\operatorname{Pr}(>|\mathbf{z}|)$ \\
\hline SPSC - CPSC & $-0,44254$ & 0,10808 & $-4,095$ & $<0,001$ \\
\hline SPCC - CPSC & $-0,34$ & 0,15836 & $-2,147$ & 0,130 \\
\hline CPCC - CPSC & $-0,39854$ & 0,19873 & $-2,005$ & 0,176 \\
\hline SPCC - SPSC & 0,10253 & 0,15836 & 0,647 & 0,912 \\
\hline CPCC - SPSC & 0,044 & 0,19873 & 0,221 & 0,996 \\
\hline CPCC - SPCC & $-0,05853$ & 0,23023 & $-0,254$ & 0,994 \\
\hline
\end{tabular}

Fuente: elaboración propia

Para la enfermedad de Bronquitis, el tratamiento sin propóleos sin inoculación de cepa bacteriana tuvo mayor promedio del logaritmo del título de Bronquitis que los tratamientos con propóleos y sin propóleos y sin inoculación de cepa bacteriana, y el tratamiento con propóleos con inoculación de cepa bacteriana tuvo mayor promedio que los tratamientos con y sin propóleos sin inoculación de cepa bacteriana, al nivel de significancia del 5\% (tabla 27).

Tabla 27. Comparaciones múltiples con el método de Tukey, para el logaritmo del título de Bronquitis

\begin{tabular}{|c|c|c|c|c|}
\hline & Estimado & Error estándar & valor $\mathrm{z}$ & $\operatorname{Pr}(>|\mathrm{z}|)$ \\
\hline SPSC - CPSC & $-0,2909$ & 0,1211 & $-2,402$ & 0,0716 \\
\hline SPCC - CPSC & 0,7903 & 0,1775 & 4,454 & $<0,001$ \\
\hline CPCC - CPSC & 0,6695 & 0,2227 & 3,007 & 0,013 \\
\hline SPCC - SPSC & 1,0812 & 0,1775 & 6,093 & $<0,001$ \\
\hline CPCC - SPSC & 0,9604 & 0,2227 & 4,313 & $<0,001$ \\
\hline CPCC - SPCC & $-0,1208$ & 0,2581 & $-0,468$ & 0,9641 \\
\hline
\end{tabular}

Fuente: elaboración propia 


\section{Discusión}

Este estudio tiene como propósito determinar el efecto de la adición de propóleos en el agua de bebida de aves de engorde, y su efecto sobre parámetros zootécnicos y la inmunidad en aves, desafiados con una cepa de referencia de E. coli.

Los resultados muestran que en el experimento uno, las aves que consumieron propóleos tuvieron más peso, tanto hembras como machos, comparados con las que no consumieron propóleos a la semana seis. Esto muestra que la suplementación de este producto natural proveniente de las abejas puede coadyuvar a mejor ganancia de peso, principalmente en los machos de engorde, ya que los pesos promedio para los machos alimentados con propóleos fueron superiores a partir de la semana dos hasta la semana seis, mientras que las hembras alimentadas con propóleos solo tuvieron pesos promedio superiores hacia la semana seis.

Adicionalmente, se investigó el efecto de propóleos en la dieta alimenticia cuando las aves son sometidas a un desafío bacteriano. Esto se estableció en el experimento dos. Se encontraron diferencias entre las dos replicaciones, en cuanto al peso, al día cero del desafío bacteriano (correspondiente al día 28 de edad de las aves). La replicación dos tuvo pesos más bajos a los días 28, 35 y 39 comparado con la replicación uno en todos los tratamientos. Los grupos que tuvieron el desafío microbiano presentaron un promedio de 150 gramos de peso más bajo que el grupo control sin desafío bacteriano al día 40, con independencia del consumo de propóleos. Sin embargo, estas diferencias en el peso no fueron significativas al día 28 de edad, o sea al momento del desafío.

Se encontró diferencia significativa en el peso entre los grupos suplementados con propóleos con y sin cepa bacteriana al día 35, siendo mayor el peso para el grupo sin propóleos. En este caso, la suplementación con propóleos no mostró ser efectiva para mantener el peso en aves con desafío bacteriano al día 35 de edad (7 días después de la inoculación de la cepa bacteriana). También hubo diferencias significativas en el peso promedio entre los grupos con propóleos con cepa y sin propóleos sin cepa al día 39, lo que está en línea con los resultados del día 35, en los que no se observó una mejora en el peso en los animales con cepa y con propóleos.

La conversión a los días 28, 35 y 39 fue mejor en el grupo sin propóleos sin cepa, seguidos por el grupo con propóleos sin cepa, y la conversión más alta se presentó en el grupo con propóleos con cepa. Sin embargo, las aves del primer experimento tuvieron mejor conversión cuando fueron suplementadas con propóleos.

La mortalidad no fue diferente entre los grupos de tratamiento, en los experimentos uno y dos. Esto se puede interpretar como que la suplementación con propóleos, aunque produce efecto sobre algunos parámetros zootécnicos como la conversión y el peso en animales con y sin desafío bacteriano, no tiene efectos sobre la mortalidad.

Con respecto a los títulos de anticuerpos para Gumboro al final del periodo de producción, en las aves sin desafío bacteriano, el grupo suplementado con propóleos tuvo títulos significativamente más altos que el grupo sin suplementación. Se puede concluir que el propóleo puede activar el sistema inmune asociado con la protección conferida por las vacunas de Gumboro.

Adicionalmente, en las aves suplementadas con propóleos, se encontraron títulos más altos en el tratamiento sin cepa comparados con el tratamiento con desafío bacteriano. Aunque se observó un estímulo inmune en las aves alimentadas con propóleos, este efecto se vio alterado en las aves desafiadas con una cepa bacteriana de E. coli.

En relación con el Newcastle, en los grupos de tratamiento que no recibieron desafío bacteriano, las aves con suplementación con propóleos mostraron títulos significativamente más altos que las aves sin suplementación, lo cual sugiere un estímulo inmune positivo mediado por el propóleo.

Para bronquitis, hubo significativamente mayores títulos en el grupo de tratamiento sin propóleos con cepa bacteriana, comparado con los grupos sin desafío bacteriano en los tratamientos con y sin suplementación con propóleos.

En este resultado, se presenta un mensaje en contravía de lo observado para Gumboro y Newcastle, ya que la no adición de propóleos con cepa bacteriana presenta mejores títulos que los grupos sin desafío y sin propóleos, lo cual indica que no existe una respuesta positiva a la adición de propóleos en el agua que aumente los títulos de la respuesta inmunológica a la enfermedad Bronquitis infecciosa. Esto da pie para una nueva investigación. Sin embargo, el grupo que fue suplementado con propóleos con cepa bacteriana tuvo títulos significativamente más altos que los grupos sin desafío bacteriano en los tratamientos con y sin suplementación con propóleos, lo que se encuentra en línea con los hallazgos del estudio para Gumboro y Newcastle. 
El propóleo presenta beneficios en animales sin eventos de enfermedad bacteriana, pero no protege o no mejora los parámetros de animales desafiados, aunque se ve un efecto positivo sobre la respuesta inmune para agentes tales como Gumboro y Newcastle.

\section{Conclusiones}

$\mathrm{Al}$ realizar la toma de las muestras de propóleos de las regiones de Santander, se demostró la presencia de diferentes compuestos de flavonoides en su contenido, debido a la variedad de flora existente en cada región. Se utilizó la metodología de cromatografía y se obtuvo que la muestra adquirida en el municipio de San Gil presentó una concentración de Apigenina de $10 \mathrm{ug} / \mathrm{ml}$, Narigenina de 63 ug/ml, Kaempferol de 15 ug/ml, superior a las demás muestras.

El extracto etanólico presentó una perfecta dilución y homogenización en el agua de bebida de las aves, permitiendo su consumo en forma normal.

El extracto etanólico de propóleos disueltos en el agua a una dosificación del 20\%, al comparar el comportamiento del peso de las aves durante los cuarenta días del tratamiento, se pudo demostrar que los pesos analizados por estadística descriptiva en los grupos de machos y hembras que consumieron propóleos fueron mayores que los lotes testigos, con lo que se encontró un beneficio para la industria avícola.

La conversión alimenticia alcanzada por las aves del grupo machos y hembras que consumieron propóleos fue menor que la de los grupos que no consumieron propóleos. Este dato es de suma importancia en la parte económica de la industria, ya que la conversión alimenticia representa la cantidad de gramos de alimento consumida en relación con peso de carne obtenido y es evaluativo para el costo de producción de kilo de carne.

En el experimento 1, se pudo comprobar el beneficio de la aplicación del extracto etanólico de propóleos en relación con el incremento de peso alcanzado por las aves. En el experimento 2, los resultados obtenidos nos demuestran que el grupo sin propóleos sin cepa fue el que obtuvo el mayor peso siguiendo en orden descendente el grupo de aves.

En el experimento 2, los resultados obtenidos en cuanto al incremento de peso nos muestran que, en la replicación 1 , los grupos que recibieron propóleos tuvieron un promedio mayor y una mayor variabilidad que los grupos que no recibieron propóleos, mientras que, en la replicación 2, los grupos que no fueron inoculados con la bacteria y el grupo sin propóleos tuvieron mayor peso, lo que también ocurrió en los grupos que fueron inoculados con la bacteria. Posiblemente debido al estrés que sufren las aves por el manejo al inocular la bacteria.

Al utilizar el extracto etanólico de propóleos e inocular las aves con la bacteria E. coli de referencia, se observó que ningún grupo de las aves estudiadas sufrió la sintomatología causada por esta.

Se demostró que las aves que no recibieron la cepa bacteriana obtuvieron menor conversión alimenticia y se evidenció así la importancia de la sanidad en el desarrollo del pollo. Sin embargo, las aves que fueron inoculadas con la bacteria E. coli y que recibieron propóleos fueron las que le siguieron al lote que obtuvo la menor conversión alimenticia.

Los informes zootécnicos obtenidos en relación con la mortalidad mostraron que el uso del extracto de propóleos no incidió sobre sus resultados.

La respuesta inmunológica para la enfermedad de Gumboro medida por la prueba ELISA mostró títulos mayores en las aves que consumieron propóleos contra el lote control.

Los títulos de la enfermedad Newcastle presentaron la misma tendencia que los de Gumboro, al demostrar que el uso del extracto etanólico de propóleos en el agua de bebida mejora la respuesta inmunológica contra estas dos enfermedades.

Para la enfermedad de Bronquitis infecciosa, las aves que no consumieron propóleos presentaron títulos mayores respecto a las que consumieron, por tal razón se requiere hacer nuevas investigaciones sobre el coronavirus agente productor de esta enfermedad viral.

\section{Agradecimientos}

Los autores agradecen a la Universidad Santo Tomás por la financiación del proyecto "Evaluación del efecto del extracto etanólico de propóleos en el desarrollo y la inmunidad de pollos de engorde en el centro experimental El Limonal de Piedecuesta, Santander".

\section{Referencias}

[1] Federación Nacional de Avicultores de Colombia (FENAVI). Avicultura, por la senda de la consolidación. Avicultores. 2014;(213):12-4. 
[2] Gimeno O, Ortega C. Antibioterapia y salud pública veterinaria; desarrollo de microorganismos resistentes, mecanismos de resistencia y estrategias para el uso prudente de antibióticos. Documento presentado en: Seminario "A problemática dos resíduos medicamentosos e contaminantes em produção animal e Saúde Pública”. 2005 nov 4; Évora, Portugal.

[3] Ranilla MJ, Carro MD. Antibióticos: debates sobre la resistencia antimicrobiana. Mundo ganadero. 2002;(249):82-5.

[4] Torres C, Zarazaga M. Antibióticos como promotores del crecimiento en animales. ¿Vamos por el buen camino? Gaceta Sanitaria. 2002;16(2):109-12.

[5] Cancho B, García MS, Simal J. El uso de los antibióticos en la alimentación animal: perspectiva actual. Cienc. Tecnol. Aliment. 2000;3(1):39-47.

[6] Márquez D. Residuos químicos en alimentos de origen animal: problemas y desafíos para la inocuidad alimentaria en Colombia. Revista Corpoica, Ciencia y Tecnología Agropecuaria. 2008;9(1):124-35.

[7] Organización de las Naciones Unidas para la Agricultura y la Alimentación (FAO) y Organización Mundial de la Salud (oms). La necesidad de fortalecer los programas nacionales de monitoreo del uso de los antimicrobianos en medicina veterinaria en la región. Documento presentado en: Conferencia Regional sobre la Inocuidad de los Alimentos para las Américas y el Caribe. 2005 dic 6-9; San José de Costa Rica.

[8] Ortiz M, Aracely P. Utilización dealternativas naturales a los antibióticos promotores del crecimiento en la salud intestinal y parámetros productivos de pollos broilers [tesis de grado]. [Valparaíso]: Universidad Católica de Valparaíso; 2004.

[9] Fajardo-Zapata AL, Méndez-Casallas FJ, Molina LH. Residuos de fármacos anabolizantes en carnes destinadas al consumo humano. Universitas Scientiarum. 2011;16(1):77-91.

[10] Noor El-Deen AI, Mona SZ, Shalaby SI, Nasr S. Propolis, with Reference of Chemical Composition, Antiparasitic, Antimycotic, Antibacterial and Antiviral Activities: A Review. Life Science Journal. 2013;10(2):1308-31.

[11] Wagh VD, Borkar RD. Indian Propolis: A Potential Natural Antimicrobial and Antifungal Agent.
International Journal of Pharmacy and Pharmaceutical Sciences. 2012;4(4):12-7.

[12] Mirzoeva OK, Grishanin RN, Calder PC. Antimicrobial Action of Propolis and Some of its Components: The Effects on Growth, Membrane Potential and Motility of Bacteria. Microbiol Res. 1997;152(3):239-46.

[13] Muñoz LC, Linares SE, Narváez W. Propiedades del propóleo como aditivo natural funcional en la nutrición animal. Biosalud. 2011;10(2):101-11.

[14] Hughes DA. Effects of Dietary Antioxidants on the Immune Function of Middle-Aged Adults. Proc Nutr Soc. 1999;58(1):79-84.

[15] Wiltrout RH, Boyd MR, Back TC, Salup RR, Arthur JA, Homung RL. Flavone-8-Acetic Acid Augments Systemic Natural Killer Cell Activity and Synergizes with il-2 for Treatment of Murine Renal Cancer. J Immunol. 1998;140(9):3261-5.

[16] Danert FC, Zampini C, Ordonẽz R, Maldonado L, Bedascarrasbure E, Isla MI. Nutritional and Functional Properties of Aqueous and Hydroalcoholic Extracts from Argentinean Propolis. Nat Prod Commun. 2014;9(2):167-70.

[17] Gil M, Perelli A, Alvarado R, Arias Y, Blumenthal E. Actividad bacteriostática y bactericida de la tintura de propóleos sobre bacterias enteropatógenas. Salus. 2012;16(3):29-37.

[18] Isla MI, Salas A, Danert FC, Zampini IC, Ordoñez RM. Analytical Methodology Optimization to Estimate the Content of Non-Flavonoid Phenolic Compounds in Argentine Propolis Extracts. Pharm Biol. 2014;52(7):835-40.

[19] Manrique AJ, Santana WC. Flavonoids, Antibacterial and Antioxidant Activities of Propolis of Stingless Bees, Melipona Quadrifasciata, Melipona Compressipes, Tetragonisca Angustula, and Nannotrigona sp. from Brazil and Venezuela. Zootecnia Tropical. 2008;26(2):157-66.

[20] Asis M. El propóleo: un valioso producto apícola. La Habana: Centro de Información y Documentación Agropecuario; 1979.

[21] Netíková L, Bogusch, Heneberg P. Czech EthanolFree Propolis Extract Displays Inhibitory Activity against a Broad Spectrum of Bacterial and Fungal Pathogens. J. Food Sci. 2013;78(9):1421-9.

[22] Carrillo ML, Castillo LN, Mauricio R. Evaluation of Antimicrobial Activity of Extracts of Huasteca 
Potosina Propolis. Información Tecnológica. 2011;22(5):21-8.

[23] Valles JG, Principal J, Barrios C. Immunomodulatory Property of Ethanolic Estract of Propolis on the Bursa of Fabricio in F1 Male Babies Chicken Rhode Island Red X Rhode Island White. Zootecnia Tropical. 2011;29(2):161-168.
[24] The R-Core Team. R: A Language and Environment for Statistical Computing. Vienna: R Foundation for Statistical Computing; 2013.

[25] Richard JJ. Ascites in Poultry. Avian Pathology. 1993;22(3):419-54. 